\title{
Aprioristic Estimation of Back Pain Risk, Connected with Work at Workers of The Metallurgical Enterprise
}

\author{
Bazarova EL*, Roslaya NA, Osherov IS and Nasybullina GM \\ Medical Unit Tirus, Verkhnyaya Salda, Russia
}

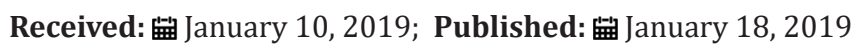

*Corresponding author: Bazarova EL , Medical Unit Tirus, Verkhnyaya Salda, Ekaterinburg, Russia

\section{Opinion}

Back pain is one of the main reasons of time invalidity working, bringing physical sufferings and considerably worsening quality of life. Illnesses of a back have the difficult multifactorial nature. Among the reasons, their causing, are allocated professional and nonprofessional. The work purpose - to spend an aprioristic estimation of professional risk of development of risk of the illnesses accompanied by back pains, in a number of trades of modernised sites of the modern metallurgical enterprise for a substantiation of preventive measures. Volume and methods. Research was spent at the large metallurgical enterprise. For an estimation of communication of illnesses of a back with work model [1] is used, created by a method of demonstrative medicine - the metaanalysis over 40 epidemiological works [1], and also methodology of the analysis of professional risk of Scientific Research Institute of Medicine of work of an academician NF Izmerov [2]. As professional risk factors of illnesses of a back in model Lotters $\mathrm{F}$ et al. lifting and moving of cargoes manually, inclinations or trunk turns, the general vibration and low satisfaction by the work, estimated in points under the special table, depending on a low or high level of a factor are used.

The score under all factors from 0 to 22 corresponds to different probability of development of back pains. As a measure of communication of illnesses of a back with work etiological fraction $\mathrm{EF}$ of the contribution of production factors of risk in development back pain is accepted. Calculation of a score and etiological fraction in separate professional groups, taking into account levels of harmful production factors, was made by us for the experience of work of 20 years, corresponding to the average experience of work at the enterprise. To criteria of professional conditionality (a score more than 12, EF more than $50 \%$ ) answered disease at mason-stove-makers- $\mathrm{EF}=62 \%$, smiths-foremen press complexes and carvers of metal on scissors - $61 \%$, metallizators, carvers of metal on saws - $58 \%$, copper-smiths of a site of welding of packages, stackers-packers of pipes electro welding manufactures, milling-machine operators - $57 \%$, hot metal millmans, operators of installations hydro abrasive are sharp, smiths-drivers of autoloaders - $54 \%$, founders electron beam fusion and electro welders - $53 \%$, that is at persons of professional groups working conditions in which are characterized by the greatest indicators of lifting and moving of cargoes manually, inclinations and turns of a trunk, the general vibration.

\section{Conclusion}

Persons of the listed trades of the studied metallurgical enterprise concern group of the raised risk of development back pain, connected with work, and need medical monitoring for the purpose of timely revealing of diseases, treatment and rehabilitation. Working out of technical and organizational measures on industrial sites on minimization of professional risk by influence on operated factors of the industrial environment and labour process is necessary.

\section{Reference}

1. Lotters F, Burdorf A, Kuiper J, Miedema H (2003) Model for the workrelatedness of low-back painScand J. Work Environ Health 29(6): 431440.

2. (2010) Prediction of the impact of harmful factors of working conditions and the assessment of occupational risk to the health of workers (guidelines). Issue 8. Approved. Scientific Council No. 45 Medical and environmental problems of workers health of the Russian Academy of Medical Sciences November 9, 2010 Moscow: Scientific Research Institute of Medical Academy of Medical Sciences 2010: 55. 
ISSN: 2574-1241

DOI: 10.26717/BJSTR.2019.13.002383

Bazarova EL. Biomed J Sci \& Tech Res

(C) (i) This work is licensed under Creative

Submission Link: https://biomedres.us/submit-manuscript.php

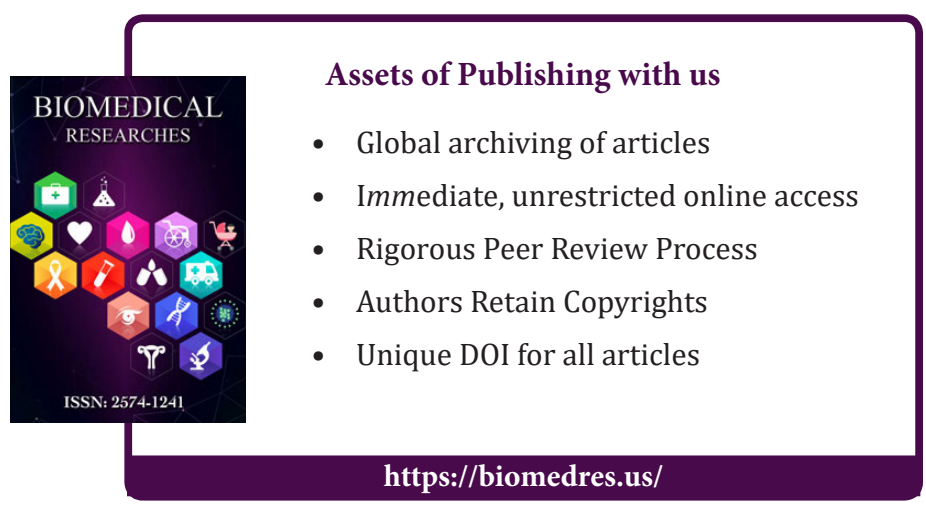

